\title{
Sıcak Presleme Yöntemiyle Üretilmiş B4C Takviyeli AA 7xxx Matrisli Fonksiyonel Derecelendirilmiş Malzemelerin Çapraz Kırılma Dayanımının Belirlenmesi
}

\author{
Hanifi ÇINICİ ${ }^{1} \&$, Uğur GÖKMEN ${ }^{1}$, Görkem KIRMIZI ${ }^{1}$, Ruziye ÇAMKERTEN ${ }^{1}$ \\ ${ }^{1}$ Metal Eğitimi Bölümü, Teknik Eğitim Fakültesi, Gazi Üniversitesi, Ankara, Türkiye \\ $\bowtie$ : hcinici@gazi.edu.tr
}

\author{
Geliş (Received):25.04.2017～Düzeltme (Revision):23.05.2017～Kabul (Accepted): 01.06.2017
}

\begin{abstract}
Öz
Bu çalışmada sıcak presleme yöntemiyle AA 7075 Al alaşımı tozları ve B4C parçacıkları ile fonksiyonel derecelendirilmiş malzemeler üretilmiştir. AA 7075 matris içerisine ağırlıkça $\% 10$ - \%60 arasında değişen oranlarda B4C ilave edilmiştir. Matris malzeme ve parçacıklar 3 boyutlu karıştırıcıda karıştırılmıştır. Karışım tozlar değişen sıcaklık $\left(250,350\right.$ ve $\left.450^{\circ} \mathrm{C}\right)$ ve basınç $(200,300$ ve 400$)$ değerlerinde preslenmiştir. Presleme işlemi sonrası 5 farklı geçiş bölgesine sahip fonksiyonel derecelendirilmiş malzemeler üretilmiştir. Geçiş bölgelerinin sertlik değişimini tespit için makro sertlik ölçümleri yapılmıştır. Üretilen numuneler tel erozyon yöntemi ile kesilerek standart boyutlarda çapraz kırılma test numuneleri elde edilmiştir. En yüksek çapraz kırılma dayanımına $450^{\circ} \mathrm{C}$ sıcaklıkta preslenen numunelerde ulaşı1mıştır
\end{abstract}

Anahtar Kelimeler: A17075, B4C, Çapraz kırma dayanımı, FDM, Sıcak presleme

\section{Investigation of Transverse Rupture Strength of AA7xxx Matrix Functional Graded Materials Reinforced $\mathrm{B}_{4} \mathrm{C}$}

\begin{abstract}
In this work, functional graded materials were produced by hot pressing with AA7075 alloy powders and $\mathrm{B}_{4} \mathrm{C}$ particles. $\mathrm{B}_{4} \mathrm{C}$ particles between $10 \%$ and $60 \%$ by weight were added to the AA 7075 matrix. Matrix materials and particles were mixed in a three dimensional mixer. The blend powders were pressed at varying temperatures (250, 350 and $\left.450^{\circ} \mathrm{C}\right)$ and pressures $(200,300$ and $400 \mathrm{MPa})$. Functionally graded materials with 5 different transition zones were produced after pressing. Macro hardness measurements were made to determine the hardness change of the transition zones. The produced specimens were cut using wire electrical discharge machining (WEDM) and transverse rupture strength test specimens were obtained in standard sizes. The maximum transverse rupture strength was reached at $450^{\circ} \mathrm{C}$ samples.
\end{abstract}

Keywords: A17075, B 4 C, Cross-crushing strength, FDM, Hot Pressing

\section{Gİiș}

Saf metaller gelișen mühendislik uygulamalarında dar bir kullanım alanına sahiptir çünkü değişken talepleri karşılamakta yetersiz kalmaktadır. Teknolojik gelişmelere paralel olarak artan ve değişen ihtiyaçların karşılanabilmesi için malzemelerde kademeli veya değişken (heterojen) yapılara ihtiyaç duyulmuştur. Son y1llarda katmanlı veya kademeli yapılara örnek olarak fonksiyonel derecelendirilmiş malzemelere (FDM) sıklıkla rastlanmaktadır. 1971'de yayınlanan "İşlevsel Dereceli Materyaller Üzerinde Ön Hazırlık" başlıklı bir makale, kademeli malzemeler kavramının ilk kullanıldığı makale olarak gösterilebilir [1,2]. Fonksiyonel derecelendirilmiş malzemeler kavramı 1984 yılında bir grup Japon bilim insanı tarafindan ortaya çıkarılmıştır [3]. Fonksiyonel derecelendirilmiş malzemelerde fiziksel ve kimyasal olarak birbirlerinden farklı özellikler taşıyan iki madde arasında faklı 1 sıl genleşme katsayılarından dolayı oluşan ısıl gerilmeler derecelendirilmiş yapılarıyla azaltılır, iki malzeme arasında ani değişmelerden dolayı meydana gelebilecek olumsuzluklar minimize edilebilir $[4,5]$.

Başta yüksek sıcaklık uygulamaları olmak üzere, uzay araçları, elektronik endüstrisi ve özellikle son yıllarda medikal uygulamalarda FDM yapılar sıklıkla kullanılmaya başlanmıştır [6]. Seramik-metal kompozitler yüksek dayanım ve sertlikle birlikte yüksek kırılma tokluğu, aşınma ve termal drenç gibi özelliklerin bir kombinasyonuna sahip olmalıdır. Bu gibi özellikler FDM'ler ile sağlanabilir [2].

Fonksiyonel derecelendirilmiş malzemeler ihtiyaç duyulan tasarıma bağlı olarak farklı yöntemler ile üretilebilirler. Fonksiyonel derecelendirilmiş malzeme üretiminde geniş bir alanda malzeme kullanımına olanak sağladığ 1 için toz metalurjisi yöntemi dikkat çekmektedir. Fonksiyonel derecelendirilmiş malzeme 
üretiminde kullanılan toz metalurjisi yöntemi birkaç temel adımdan oluşmaktadır. İlk adımda tozları ön tasarıma göre tartma ve karıştırma vardır. Bir diğer adımda ise karışım tozları önceden şekli belirlenmiş kalıp içerisine uygun şekilde dağıtma ve devamında istifleme-sıkıştırma bulunmaktadır. İmalatın son safhasında ise tam yoğunluğa ulaşmak için sinterleme yapılmaktadır $[4,7,8]$.

\section{DENEYSEL ÇALIŞMALAR}

FDM üretimi için yapılan deneysel çalışmalarda A17075 $(<150 \mu)$ tozu ile $\mathrm{B}_{4} \mathrm{C} \quad(<10 \mu)$ tozları her kademe için ayrı ayrı tartılarak hazırlamış ve üç boyutlu karıştırıcıda karıştırılmıştır. Her bir kademe için ayrı ayrı hazırlanan karışım tozlar sıcak presleme kalıbı içerisine 6 kademeyi oluşturacak şekilde yerleştirilmiştir (Şekil 1). Sıcak presleme işleminde presleme sıcaklığ 350 ve $450^{\circ} \mathrm{C}$, presleme basıncı olarak da 200, 300 ve $400 \mathrm{MPa}$ basınç değerleri kullanılmıştır. Sıkıştırma sonras1 60x60x10 mm boyutlarında üretilen FDM'ler ASTM B528-05 standardına göre kesilerek $31,7 \times 12,7 \times 6,35 \mathrm{~mm}$ botutlatında çapraz kırma numuneleri haline getirilmiştir. Elde edilen numuneler $50 \mathrm{kN}$ kapasiteli Instron 3369 çekme/basma cihazında çapraz kırılma dayanımı testi yapılmıştır.

FDM'lerin kademeleri içerisinde bulunan toz miktarları ve geçiş bölgeleri Şekil 5.9'da şematik olarak gösterilmiştir. AA 7075 serisi matris içerisinde bulunan $\mathrm{B}_{4} \mathrm{C}$ parçacıkların miktarı en alt kademe de ağırlıkça $\% 10$ olmak üzere yukarı doğru $\% 10$ oranında arttırılmıştır.

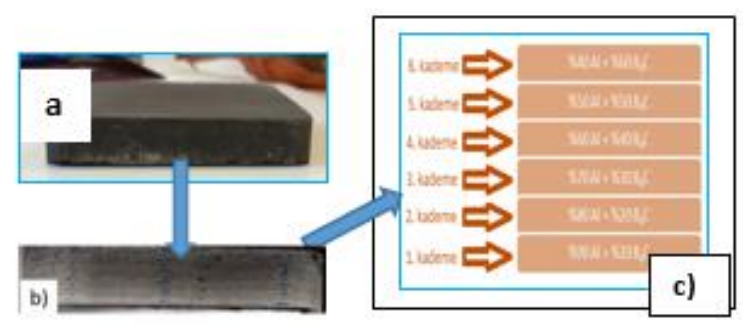

Şekil1. a) FDM'nin makro resmi, b) Kademelere gösteren resim, c) Kademelerin şematik gösterimi.

\section{BULGULAR ve TARTIŞMA}

Üretilen FDM'lerin her bir kademesinden (6 kademe) SEM görüntüleri alınmış ve elde edilen görüntüler doğrultusunda değerlendirmeler yapılmıştır. Farklı presleme sicaklıklarında $\left(250,350,450^{\circ} \mathrm{C}\right)$ ve presleme basınçlarında $(200,300,400 \mathrm{MPa})$ elde edilen FDM'lerin 6. kademelerine ait SEM görüntüleri Şekil 2'de verilmiştir.

Kullanılan bütün basınç ve sıcaklık değerlerinde artan $\mathrm{B}_{4} \mathrm{C}$ miktarına bağlı olarak gözenekli yapının arttığ gözlenmiştir. $\mathrm{B}_{4} \mathrm{C}$ miktarındaki artışa paralel olarak sertliğin artması ile uygulanan basınç ile Al 7075 tozlarında tabakalanmaların olduğu düşünülmektedir.
$200 \mathrm{MPa}$ presleme basincında üretilen FDM'lerin 6 . Kademelerine ait resimlerde presleme sicaklığının artmasına bağlı olarak partikül-matris arayüzeyünde meydana gelen mükro boşlukların azaldığı görülmektedir. 250 ve $350 \mathrm{C}$ presleme sıcaklığında üretilen FDM'lerde partikül-matris arayüzeylerinde hem uyumsuzlukların hem de mikro boşlukların fazla olmuştur. $450 \mathrm{C}$ presleme sıcaklığında üretilen FDM'lerde ise hem partikül-matris arayüzey boşluklarının azaldığı hem de partikül-matris uyumunun arttığı gözlemlenmiştir.

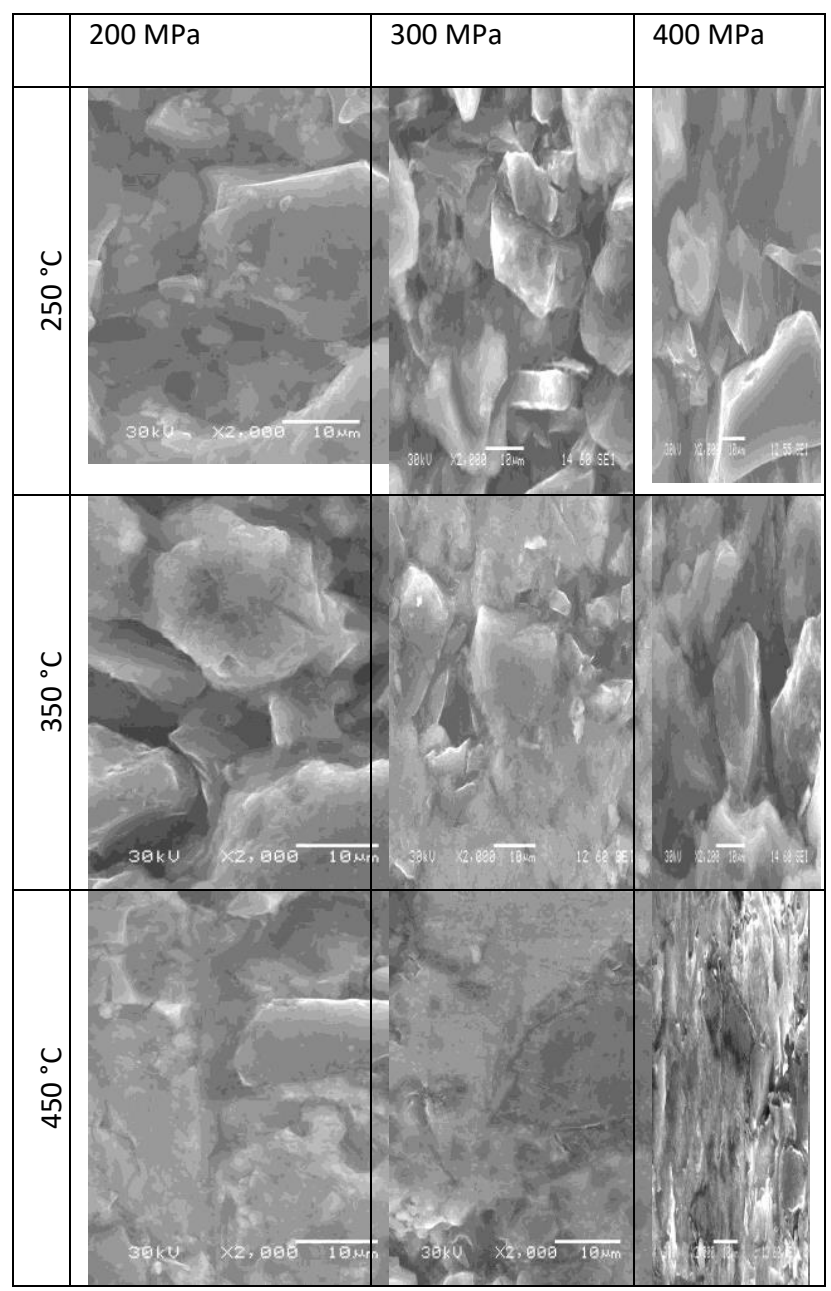

Şekil 2. FDM'lerin 6. kademelerine ait SEM görüntüleri

Şekil 3'te farklı sıcaklık ve basınçlarda üretilen FDM'lerin kademelerinin sertlik değişimini gösteren grafikler gösterilmiştir. Grafikler incelendiğinde, kademelerdeki partikül oranının artışına bağlı olarak sertlik değerlerinin artmasına neden olmuştur. Verilen grafiklerde sabit sicaklıklarda presleme basincının artmasına bağlı olarak kademelerdeki sertlik değerlerinin arttığı görülmüştür. $250^{\circ} \mathrm{C}$ ve $350^{\circ} \mathrm{C}$ sicaklıklarda üretilen FDM'lerin kademelerinin sertlik değerleri yakın değerlerdeyken $450^{\circ} \mathrm{C}$ sicaklıklarda üretilen FDM'lerin kademelerinde sertlik değerlerinin yaklaşık olarak \%20 oranında bir artış olduğu tespit edilmiştir. Bu durumun, sıcaklık ve basıncın artmasına 
bağlı olarak matris/partikül ara yüzey uyumunun ve matris yap1 içerisindeki mikro boşlukların daha az olmasından kaynaklandığı düşünülmektedir.
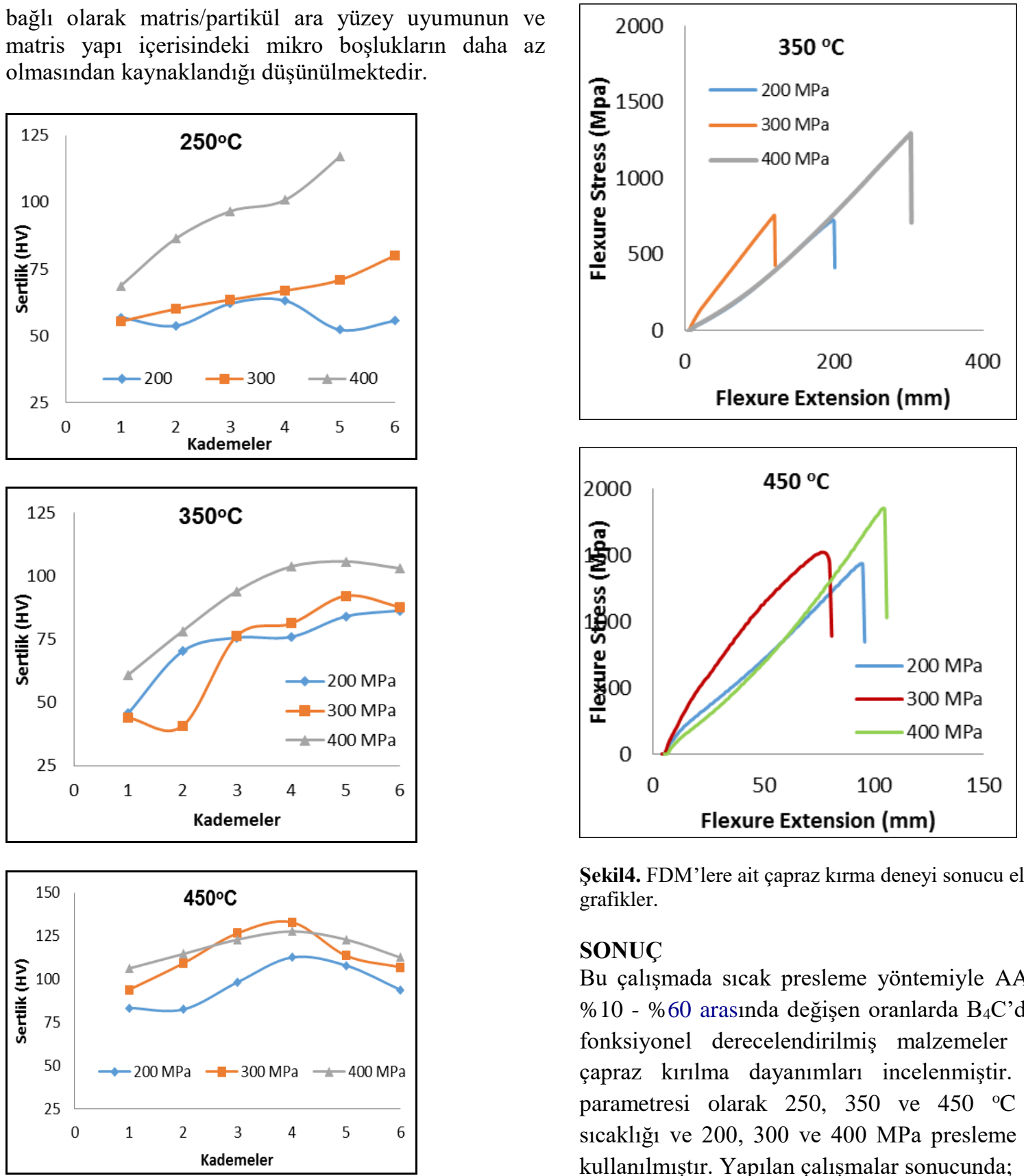

Şekil3. FDM'lerin kademelerinde sertlik değişimi.

Şekil 4'te 250,350 ve $450{ }^{\circ} \mathrm{C}$ presleme sicaklığg ve 200 , 300 ve $400 \mathrm{MPa}$ presleme basıncı kullanılarak üretilen FDM'lere ait çapraz kırma deneyi sonucu elde edilen grafikler verilmiştir. Grafikler incelendiğinde, her üç sıcaklıkta da presleme basıncının artması çapraz kırma dayanımının artmasına neden olmuştur. $250 \quad{ }^{\circ} \mathrm{C}$ presleme sıcaklığında üretilen FDM'lerde çapraz kırma dayanımı yaklaşık $500 \mathrm{MPa}, \quad 350{ }^{\circ} \mathrm{C}$ presleme sıcaklığında yaklaşık $1300 \mathrm{MPa}$ ve $450{ }^{\circ} \mathrm{C}$ presleme sicaklığında ise yaklaşık $1800 \mathrm{MPa}$ olmuştur.

Şekil4. FDM'lere ait çapraz kırma deneyi sonucu elde edilen grafikler.

\section{SONUÇ}

Bu çalışmada sıcak presleme yöntemiyle AA 7075 ve $\% 10$ - \%60 arasında değişen oranlarda $\mathrm{B}_{4} \mathrm{C}$ 'den oluşan fonksiyonel derecelendirilmiş malzemeler üretilerek çapraz kırılma dayanımları incelenmiştir. Üretim parametresi olarak 250, 350 ve $450{ }^{\circ} \mathrm{C}$ presleme sıcaklığı ve 200, 300 ve $400 \mathrm{MPa}$ presleme basınçları kullanılmıştır. Yapılan çalışmalar sonucunda;

Presleme sıcaklığı ve basıncının artmasına bağlı olarak hem partikül-matris ara yüzey boşluklarının azaldığ hem de partikül-matris uyumunun arttığ gözlemlenmiştir.

Sabit sıcaklıklarda presleme basıncının artmasına bağlı olarak kademelerdeki sertlik değerlerinin arttığ görülmüştür.

Presleme sıcaklığı ve basıncının artması çapraz kırma dayanımının artmasına neden olmuştur.

\section{TEŞEKKÜR}

Bu çalışmayı 214M112 proje numarası ile destekleyen TÜBİTAK'a teşekkürlerimizi sunarız. 


\section{KAYNAKÇA}

[1] Neubrand A., Neubrand J. Gradient materials: an overview of a novel concept, Zeitschrift fur Metallkunde, 88, 358-371, 1997.

[2] Zygmuntowicz J., Miazga A., Konopka K., Kaszuwara W., Metal Particles Size Influence On Graded Structure In Composite $\mathrm{Al}_{2} \mathrm{O}_{3}-\mathrm{Ni}$, Materials and Technology, 50, 537- 541, 2016.

[3] Zhang X., Zhang H. Optimal design of functionally graded foam material under impact loading, International Journal of Mechanical Sciences, 68, 199-211, 2013.

[4] Mahamood R. M., Akinlabi E. T., Shukla M., Pityana S. Functionally Graded Material: An Overview, 3, 15931597, 2012.

[5] Taheri A. H., Hassani B., Moghaddam N. Z. Thermoelastic optimization of material distribution of functionally graded structures by an isogeometrical approach, International Journal of Solids and Structures, 51, 416-429, 2014.

[6] Mehboob H., Chang S. H. Evaluation of the development of tissue phenotypes: Bone fracture healing using functionally graded material composite bone plates, Composite Structures, 117, 105-113, 2014.

[7] Zhu J., Lai Z., Yin Z., Jeon J., Lee S. Fabrication of $\mathrm{ZrO}_{2}-\mathrm{NiCr}$ functionally graded material by powder metallurgy, Materials Chemistry and Physics, 68, 130$135,2001$.

[8] Nemat-Alla M. M., Ata M. H., Bayoumi M. R., KhairEldeen W. Powder metallurgical fabrication and microstructural investigations of Aluminium/Steel functionally graded material, Materials Sciences and Applications, 2, 1708-1718, 2011. 